\title{
Cognitive and Sensory Declines in Old Age: Gauging the Evidence for a Common Cause
}

\author{
Ulman Lindenberger \\ Max Planck Institute for Human Development \\ and Saarland University
}

\author{
Paolo Ghisletta \\ Max Planck Institute for Human Development, University of \\ Geneva, and Distance Learning University, Switzerland
}

\begin{abstract}
Resource accounts of behavioral aging postulate that age-associated impairments within and across intellectual and sensory domains reflect, in part, a common set of senescent alterations in the neurochemistry and neuroanatomy of the aging brain. Hence, these accounts predict sizeable correlations of between-person differences in rates of decline, both within and across intellectual and sensory domains. The authors examined reliability-adjusted variances and covariances in longitudinal change for 8 cognitive measures and for close visual acuity, distant visual acuity, and hearing in 516 participants in the Berlin Aging Study (ages 70 to 103 years at 1st measurement). Up to 6 longitudinal measurements were distributed over up to 13 years. Individual differences in rates of cognitive decline were highly correlated, with a single factor accounting for $60 \%$ of the variance in cognitive change. This amount increased to $65 \%$ when controlling for age at first measurement, distance to death, and risk of dementia. Contrary to expectations, the correlations between cognitive and sensory declines were only moderate in size, underscoring the need to delineate both domain-general and function-specific mechanisms of behavioral senescence.
\end{abstract}

Keywords: cognition, sensory functioning, aging, longitudinal data, random coefficient modeling

A central rationale of cognitive aging research is to ascertain both the quantity and identity of the causes that drive senescent changes in behavior (Rabbitt, 1993). According to resource accounts of behavioral aging, a large variety of the different manifestations of behavioral aging can be reduced to a few causal mechanisms acting as pacemakers of developmental change (cf. Craik, 1983; Craik \& Bialystok, 2006; Park \& Payer, 2006; Salthouse, 1996). Resource accounts carry the benefit of parsimony, but they tend to be conceptually and empirically underidentified. When taken to the extreme, the resource in question may be left unspecified, serving as a placeholder for future research. For instance, when Lindenberger and Baltes (1994; Baltes \& Lindenberger, 1997) discovered a high correlation among sensory, sensorimotor, and intellectual functioning in old age, the authors speculated about the possible existence of a common cause, or a set of common causes, driving senescent changes in all three domains of functioning. They were, however, reluctant to specify the mechanisms underlying this cause.

Meanwhile, findings from developmental behavioral neuroscience have strengthened the claim for common causes of ageassociated behavioral decline in adulthood and old age. Higher order cognitive functions that rely on the integrity of the prefrontal cortex and the medial-temporal lobes-in particular broad fluid abilities, including executive functions, working memory, and episodic memory-show pronounced normative age-related decline (Bäckman, Small, Wahlin, \& Larsson, 2000; Brehmer, Li Müller, von Oertzen, \& Lindenberger, 2007; Shing, WerkleBergner, Li, \& Lindenberger, 2008; Singer, Verhaeghen, Ghisletta,
Ulman Lindenberger, Max Planck Institute for Human Development, Berlin, Germany; School of Psychology, Saarland University, Saarbrücken, Germany. Paolo Ghisletta, Max Planck Institute for Human Development, Berlin, Germany; Faculty of Psychology and Educational Sciences, University of Geneva, Switzerland; Distance Learning University, Switzerland.

This article reports data from the Berlin Aging Study (BASE; www.base-berlin.mpg.de). The BASE was initiated by the late Paul B. Baltes (psychology), in collaboration with Hanfried Helmchen (psychiatry), Elisabeth Steinhagen-Thiessen (internal medicine and geriatrics), and Karl Ulrich Mayer (sociology). Financial support came from the Max Planck Society; the Free University of Berlin; the German Federal Ministry for Research and Technology (1989-1991, 13 TA 011 + 13 TA 011/A); the German Federal Ministry for Family, Senior Citizens, Women, and Youth (1992-1998, 314-1722-102/9 + 314-1722-102/9a); and the BerlinBrandenburg Academy of Sciences' Research Group on Aging and Societal Development (1994-1999). We acknowledge additional support from the Max Planck Society and the German Research Foundation (Cooperative Research Grant SFB 378), and we express our gratitude to all colleagues in the BASE who contributed to the work reported here.

Special thanks go to the late Paul B. Baltes and to Shu-Chen Li, Martin Lövdén, John J. McArdle, Florian Schmiedek, Tania Singer, Jacqui Smith, and Paul Verhaeghen. Analyses similar to those presented in this article were presented in the context of a plenary symposium in honor of Patrick Rabbitt at the Cognitive Aging Conference, Adelaide, Australia, in 2007, and analyses without data from the fifth and sixth measurements were presented at the Cognitive Aging Conference, Atlanta, Georgia, in 2002.

Correspondence concerning this article should be addressed to Ulman Lindenberger, Center for Lifespan Development, Max Planck Institute for Human Development, Lentzeallee 94, D-14195 Berlin, Germany, or to Paolo Ghisletta, Faculty of Psychology and Educational Sciences, University of Geneva, Boulevard du Pont d'Arve 40, 1211 Geneva, Switzerland. E-mail: lindenberger@mpib-berlin.mpg.de or paolo.ghisletta@ unige.ch 
Lindenberger, \& Baltes, 2003; West, 1996). In line with these observations, reductions in white-matter integrity and volume are particularly pronounced in prefrontal and medio-temporal areas of the brain (e.g., Raz et al., 2005, 2008; Raz, Torres, \& Spencer, 1993). Raz et al. (2005) also observed that longitudinal volume losses are correlated across regions. For instance, reliable correlations in volume changes were found for the lateral prefrontal cortex and prefrontal white matter $(r=.71)$ and for the hippocampus and prefrontal white matter $(r=.70)$. At the neurochemical level, the continuous decline of striatal and extrastriatal dopamine systems from early to late adulthood and old age is particularly prominent (for reviews, see Bäckman, Nyberg, Lindenberger, Li, \& Farde, 2006; S.-C. Li, Lindenberger, Nyberg, Heekeren, \& Bäckman, in press). Molecular imaging studies, for instance, indicate that age-related dopamine losses are powerful mediators of age-related impairments in the broad fluid ability domain and episodic memory (Bäckman, Ginovart, et al., 2000; ErixonLindroth et al., 2005; Volkow et al., 1998).

\section{This Study}

This study does not attempt to delineate the relative importance of different physiological alterations for behavioral decline during adulthood and old age. Rather, it is based on the premises that (a) senescent brain changes occur at both neurochemical and neuroanatomical levels, (b) these changes affect sensation, perception, and cognition in a correlated manner (Nagel, Werkle-Bergner, Li, \& Lindenberger, 2007; Park et al., 2004; cf. Park \& Reuter-Lorenz, 2009), and (c) individuals differ in the rate and severity of these changes. On the basis of these three premises, we predict that rates of cognitive and sensory decline in old and very old age are correlated across individuals. In analyzing correlated rates of change, our study also serves to qualify and validate the correlational link between sensory and intellectual functioning reported by Lindenberger and Baltes (1994, 1997), which was based on interindividual differences in level and not on interindividual differences in rates of intraindividual (longitudinal) change.

Existing evidence from several longitudinal studies indicates that correlations among changes in different cognitive abilities are moderate to high in samples of older adults (Anstey, Luszcz, \& Hofer, 2003; de Frias, Lövdén, Lindenberger, \& Nilsson, 2007; Ghisletta \& Lindenberger, 2003, 2005; Hultsch, Hertzog, Dixon, \& Small, 1998; Lövdén, Ghisletta, \& Lindenberger, 2004; Lövdén, Li, Shing, \& Lindenberger, 2007; MacDonald, Hultsch, \& Dixon, 2003; Schaie, Maitland, Willis, \& Intrieri, 1998; Wilson et al., 2002). The present study, which is based on data from the Berlin Aging Study (BASE; Baltes \& Mayer, 1999), adds to this evidence by combining three design features. First, the range of assessed behaviors goes beyond the cognitive domain and also includes sensory measures of visual and auditory acuity (cf. Anstey et al., 2003; Ghisletta \& Lindenberger, 2005). Second, the age of the participants is unusually high, with an average of 85 years and a minimum of 70 years at the first measurement. Within this age range, all individuals in the sample should have experienced, and will continue to experience, aging-related physiological decline. It follows that intercorrelations of change should be especially high, because the mechanisms allegedly driving these changes are fully operative. Third, the present sample was repeatedly assessed up to six times over a period of up to 13 years. The comparatively long extension and relatively high density of observations within old age make obtaining reliable estimates of between-person differences in change more likely (Hertzog, von Oertzen, Ghisletta, \& Lindenberger, 2008). The presence of reliable variance of change is a methodological precondition for examining covariances of change (cf. Ghisletta \& Lindenberger, 2004). Recent Monte Carlo simulations have shown that the statistical power to detect individual differences in change and covariance of change is very low and that adding longitudinal measurement occasions strongly enhances statistical power (Hertzog, Lindenberger, Ghisletta, \& von Oertzen, 2006; Hertzog et al., 2008).

\section{Methodological Considerations}

With regard to statistical methods, this study makes use of random coefficient modeling (RCM) to capture variances and covariances in change. RCM is closely related, and sometimes identical, to latent growth curve modeling (McArdle \& Hamagami, 1996; for a comparison of the two approaches, see Ghisletta \& Lindenberger, 2004). In the present application, RCM serves to estimate four basic statistical parameters: (a) the mean of level (also called the fixed effect of level), which denotes the average (sample) functioning at a given point in time; (b) the mean of change (fixed effect of change), which denotes the average change over time; (c) the variance of level (random effect of level), which denotes interindividual differences at that point in time; (d) the variance of change (random effect of change), which denotes interindividual differences in change over time. As a fifth parameter, the covariance between level and change denotes the extent to which the variance in level and the variance in change are related. Especially in old age, the level parameter contains an unknown quantity of earlier change (i.e., change that occurred prior to the observation period). Hence, level and change are likely to be correlated in samples of aging populations. Note also that both the level and the change parameters are latent, because they express the common variance of a given measure over time. They are thus disattenuated for occasion-specific variance and measurement error (Hertzog et al., 2008).

In its multivariate extension, RCM simultaneously estimates the fixed and random effects of level and change in more than one variable. Within the period of time considered and under certain assumptions discussed later, such as proper specification of the time dimension and sample homogeneity, the effect decomposition achieved by multivariate RCM offers a direct way to look at the extent to which interindividual differences in change are correlated among each other at a given time. Compared with univariate analyses, multivariate extensions of RCM and latent growth curve modeling to assess intercorrelations of change are not often reported in the literature, presumably because empirical underidentification often leads to convergence failures. The final multivariate RCM reported in this article simultaneously estimates the 18 random effects (11 levels and 7 slopes) that were found to differ reliably from zero in initial univariate RCM analyses. We then analyzed the resulting variance-covariance matrix of 18 random effects with a second-order exploratory factor analysis (EFA). Given that the random effects correspond to variances and covariances of latent factors, the commonality among the random slope effects provides an unbiased (i.e., reliability-adjusted) estimate of correlated change. 
Recent analyses of various longitudinal data sets have shown that rates of longitudinal change in cognitive functioning accelerate with age (de Frias, Lövdén, Lindenberger, \& Nilsson, 2007; Singer et al., 2003), dementia incidence (e.g., Sliwinski, Lipton, Buschke, \& Stewart, 1996), and distance to death (Ghisletta, McArdle, \& Lindenberger, 2006; Lindenberger, Singer, \& Baltes, 2002; Maier \& Smith, 1999; Rabbitt, Lunn, Wong, \& Cobain, 2008; for a summary, see Bäckman \& MacDonald, 2006). Hence, we report the results obtained both before and after statistically controlling for age at first occasion, distance to death, and a time-varying marker of risk of dementia that has been validated in previous analyses of this data set (Gerstorf, Herlitz, \& Smith, 2006). Conducting the analyses with and without control for these covariates allows us to estimate the extent to which the observed covariation within and between cognitive and sensory declines is induced by cross-sectional age differences, death, or cognitive pathology.

\section{Method}

\section{Participants}

The initial sample of the BASE was stratified by age (ranging from 70 to 103 years) and sex, and included 516 participants (Baltes \& Mayer, 1999). All six waves of measurement except for the second involved an initial assessment, followed by a broader intensive protocol. The second wave did not include an intensive protocol. The bottom portion of Table 1 includes the participants' average duration in the study since study inception, the longitudinal sample size, and the average sample age. The sample's survival status was obtained from the German State Registry office in September 2004. At that time, of the 516 initial participants, 404 were deceased (193 women, 211 men) and 112 were alive. An in-depth analysis of longitudinal sample attrition that separates mortality-associated and experimental components of selectivity is provided elsewhere (Lindenberger et al., 2002).
On the basis of age cohort-specific cutoffs of the Short Mini Mental State Examination, Gerstorf et al. (2006) defined a dichotomous marker of likely dementia diagnosis at each wave of the BASE. These cutoffs were shown to ensure high specificity (ranging from $72 \%$ to $98 \%$ ) and sensitivity (ranging from $62 \%$ to $88 \%$ ) of dementia classification when compared with independent clinical diagnoses of dementia based on standard clinical interviews and assessment procedures (Helmchen et al., 1999). This appraisal was performed at the initial assessment of each wave and was not recomputed at the respective intensive protocol (given that the intrawave measurements were only a few months apart from each other). From Wave 1 through Wave 6, there were, respectively, $148,117,55,32,16$, and 6 individuals considered likely to be demented by these standards. In this study, the marker of likely dementia diagnosis, though quite specific and sensitive, is used merely as a statistical control and does not represent a variable of focal interest. For this purpose, we created a wave-specific (i.e., time-varying) dummy code that assigned a 1 to those who were considered at risk at a given wave of assessment and a 0 to the others. This allowed us to estimate the effects of likely dementia diagnosis on the parameter estimates of the longitudinal models. We preferred this to the more common strategy of simply excluding demented individuals, which drastically reduces statistical power and increases sample selectivity.

\section{Tasks and Procedure}

Table 1 also provides a listing of all the variables for each wave (for in-depth descriptions and psychometric properties of all measures, see Lindenberger \& Baltes, 1997; Lindenberger, Mayr, \& Kliegl, 1993; Marsiske et al., 1999). In the cognitive domain, four intellectual abilities, each measured by two tasks, were assessed: perceptual speed (Digit Letter and Identical Pictures tasks), fluency (Category and Word Beginnings tasks), episodic memory (Paired Associates and Memory-for-Text tasks), and verbal knowl-

Table 1

Longitudinal Design of the Berlin Aging Study for Cognitive and Sensory Variables

\begin{tabular}{|c|c|c|c|c|c|c|c|c|c|c|c|}
\hline \multirow[b]{2}{*}{ Construct } & \multicolumn{11}{|c|}{ Measurement occasion } \\
\hline & $\mathrm{IA}_{\mathrm{T} 1}$ & $\mathrm{IPr}_{\mathrm{T} 1}$ & $\mathrm{IA}_{\mathrm{T} 2}$ & $\mathrm{IA}_{\mathrm{T} 3}$ & $\mathrm{IPr}_{\mathrm{T} 3}$ & $\mathrm{IA}_{\mathrm{T} 4}$ & $\mathrm{IPr}_{\mathrm{T} 4}$ & $\mathrm{IA}_{\mathrm{T} 5}$ & $\mathrm{IPr}_{\mathrm{T} 5}$ & $\mathrm{IA}_{\mathrm{T} 6}$ & $\mathrm{IPr}_{\mathrm{T} 6}$ \\
\hline Perceptual speed & \multirow[t]{4}{*}{ DL } & DL, IP & DL & DL & DL, IP & DL & DL, IP & DL & DL, IP & DL & DL, IP \\
\hline Episodic memory & & PA, MT & & & PA, MT & & PA, MT & & PA, MT & & PA, MT \\
\hline Fluency & & CA, WB & $\mathrm{CA}$ & $\mathrm{CA}$ & CA, WB & $\mathrm{CA}$ & $\mathrm{CA}, \mathrm{WB}$ & $\mathrm{CA}$ & CA, WB & $\mathrm{CA}$ & CA, WB \\
\hline Verbal knowledge & & VO, SW & & & VO, sW & & VO, SW & & VO, SW & & VO, SW \\
\hline Vision & \multirow{2}{*}{$\mathrm{CV}, \mathrm{DV}$} & & $\mathrm{CV}, \mathrm{DV}$ & $\mathrm{CV}, \mathrm{DV}$ & & $\mathrm{CV}, \mathrm{DV}$ & & $\mathrm{CV}, \mathrm{DV}$ & & $\mathrm{CV}, \mathrm{DV}$ & \\
\hline Hearing & & $\mathrm{HE}$ & HE & HE & & HE & & HE & & HE & \\
\hline \multicolumn{12}{|l|}{ Time in study } \\
\hline$M$ & 0.00 & 0.13 & 1.95 & 3.76 & 3.99 & 5.53 & 6.03 & 8.94 & 9.00 & 13.00 & 13.04 \\
\hline$S D$ & 0.00 & 0.09 & 0.71 & 0.66 & 0.69 & 0.79 & 0.80 & 0.84 & 0.86 & 0.87 & 0.88 \\
\hline$N$ & 516 & 516 & 361 & 244 & $208^{\mathrm{a}}$ & 164 & 132 & 88 & 82 & 48 & $47^{\mathrm{b}}$ \\
\hline \multicolumn{12}{|l|}{ Age } \\
\hline$M$ & 84.92 & 85.04 & 85.26 & 84.34 & 83.87 & 84.07 & 84.30 & 85.87 & 85.86 & 89.36 & 89.47 \\
\hline$S D$ & 8.66 & 8.68 & 8.41 & 7.30 & 6.91 & 6.33 & 5.90 & 4.36 & 4.48 & 4.58 & 4.60 \\
\hline
\end{tabular}

Note. $\quad$ IA $=$ initial assessment; IPr $=$ intensive protocol; T1-T6 $=$ Time 1 -Time 6; DL $=$ Digit Letter task; IP $=$ Identical Pictures task; PA $=$ Paired Associates task; MT = Memory-for-Text task; CA = Category task; WB = Word Beginning task; VO = Vocabulary task; SW = Spot-a-Word task; CV = close vision; $\mathrm{DV}=$ distant vision; $\mathrm{HE}=$ hearing.

${ }^{\mathrm{a}}$ For the entire $\operatorname{IPr}_{\mathrm{T} 3}, n_{3}=206 .{ }^{\mathrm{b}}$ For the entire $\operatorname{IPr}_{\mathrm{T} 6}, n_{6}=46$. 
edge (Vocabulary and Spot-a-Word tasks). With respect to sensory functioning, a total of three measures of vision and hearing were analyzed. Visual acuity was measured in Snellen decimal units at two different distances with two different standard reading tables containing digits and letters. Close visual acuity (close vision) was measured separately for the left and the right eye with a standard reading table presented at reading distance. Distance visual acuity (distant vision) was assessed binocularly with a reading table presented to the participants at a minimum distance of 2.5 meters. All three measurements were taken both with and without optimum optical correction (e.g., glasses) available to participants. Close vision refers to values obtained for the better eye. At the first measurement $(n=516), 92 \%$ of the participants had at least one pair of glasses. The analyses reported are based on the better values, which in most cases referred to corrected vision. As argued elsewhere (e.g., Lindenberger \& Baltes, 1994), considering corrected vision should reduce the importance of peripheral variance (e.g., variance due to individual differences in the refractory properties of the lens), thereby allowing for a more direct assessment of visual losses that are neuronal in origin. Auditory acuity was measured in decibels and assessed with a Bosch ST-20-1 pure-tone audiometer with headphones and standard audiometric procedures. Thresholds were measured separately for the right and left ears at four different frequencies $(2.00,3.00,4.00$, and $6.00 \mathrm{kHz})$. The present results are based on a single aggregate score averaged over the four frequencies.

\section{Data Analysis}

Level and change in cognitive and sensory functioning were analyzed as a linear and quadratic function of the length of time that each participant took part in the study and was measured in years. For statistical analysis, the length of each person's participation in the study was centered on the arithmetic mean of the time he or she participated in the study (cf. Mehta \& West, 2000; Rovine \& Molenaar, 1998; Wainer, 2000; see Figure 1 for illustration). Chronological age at the first measurement was centered on the sample mean and regarded as a time-invariant covariate. All

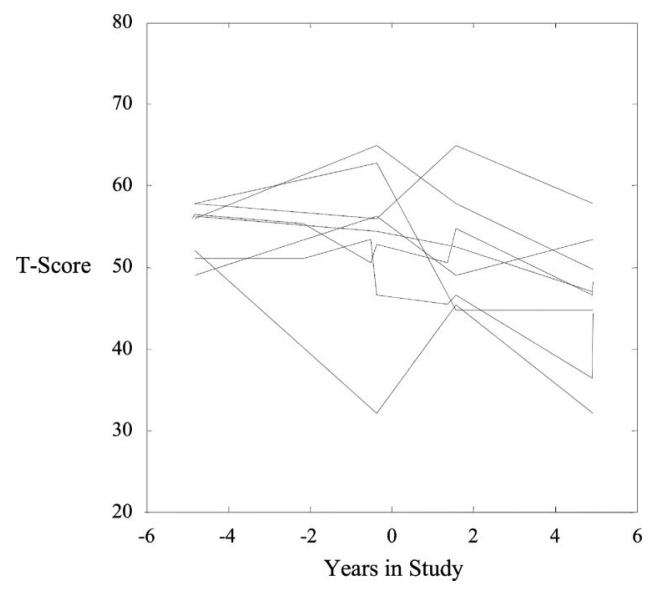

Figure 1. Time centering of data. For each individual, the intercept of time in study was shifted to the center of the assessment period (cf. Wainer, 2000) to obtain interpretable estimates of correlations between level and change. This figure displays the centered data for one individual. variables were longitudinally standardized to a $T$ score metric anchored at first measurement. This transformation retains longitudinal mean and variance information, does not alter the longitudinal correlations, and eases computation and interpretation. Subsequent data analysis then proceeded in three steps: (a) 11 univariate RCMs, 1 carried out for each cognitive and sensory variable separately, to test for the most appropriate specification of the change function for each variable; (b) 1 multivariate RCM combining and simultaneously estimating the 11 univariate RCM specifications (the multivariate model estimates reliable variances of level and change and the multivariate covariance matrix of interindividual differences in level and change); and (c) EFA on the basis of the multivariate covariance matrix. The univariate analyses were used to filter out statistically unreliable effects before examining the multivariate structure. For instance, when a given variable did not show statistically reliable interindividual differences in change in the univariate analysis, the corresponding variance term and all corresponding covariance terms were not included in the multivariate analysis (cf. Ghisletta \& Lindenberger, 2004).

To examine the influence of cross-sectional age differences, time to death, and risk of dementia, the data were analyzed without and with (a) statistical control for initial chronological age, (b) years remaining to live since first occasion, and (c) occasionspecific risk of dementia. RCM uses the full-information maximum likelihood algorithm, which accommodates incomplete data by analyzing all available data points; no participants are excluded from the analysis, and missing data are not imputed. The fullinformation maximum likelihood algorithm adjusts parameter estimates for nonrandom attrition to the extent that attrition is predicted by variables included in the model. The variables included in this article have been shown to be strong predictors of attrition in this data set (Ghisletta et al., 2006; Lindenberger et al., 2002).

\section{Results}

\section{Univariate RCMs Without Control for Age, Time to Death, and Risk of Dementia}

For each variable analyzed, columns 2-7 in Table 2 display parameters for mean level, mean of linear change, mean of quadratic change, variance of level, variance of linear change, and variance of quadratic change, respectively. All variables except vocabulary showed reliable mean linear change. As indicated by the parameters' signs, these changes were negative for all variables. Moreover, all variables displayed mean quadratic changes, which were negative in all cases except for hearing. Reliable variance in level was, of course, found in all variables. Variance in linear change was not reliable for the Word Beginning, Vocabulary, and Spot- a-Word tasks or for hearing. For the remaining five cognitive variables and two sensory variables, interindividual differences in intraindividual linear change were statistically reliable. Variance in quadratic change was reliable for the Digit Letter task and hearing only. Finally, column 8 in Table 2 displays the amount of residual variance estimated within the RCMs.

\section{Multivariate RCM Without Control for Age, Time to Death, and Risk of Dementia}

Table 3 shows the main estimated parameters of the multivariate $\mathrm{RCM}$ without control for age, time to death, and risk of dementia. 
Table 2

Univariate Multilevel Modeling Results Without Control for Age, Time to Death, Risk of Dementia, and Their Interactions

\begin{tabular}{|c|c|c|c|c|c|c|c|}
\hline \multirow[b]{2}{*}{ Construct } & \multicolumn{3}{|c|}{ Mean } & \multicolumn{4}{|c|}{ Variance } \\
\hline & Level & $\begin{array}{l}\text { Linear } \\
\text { change }\end{array}$ & $\begin{array}{l}\text { Quadratic } \\
\text { change }\end{array}$ & Level & $\begin{array}{l}\text { Linear } \\
\text { change }\end{array}$ & $\begin{array}{l}\text { Quadratic } \\
\text { change }\end{array}$ & Residual \\
\hline Digit Letter & $48.29(0.43)$ & $-0.81(0.05)$ & $-0.36(0.05)$ & $85.49(5.77)$ & $0.42(0.06)$ & $0.32(0.07)$ & $8.38(0.32)$ \\
\hline Identical Pictures & $49.77(0.47)$ & $-0.70(0.08)$ & $-0.24(0.08)$ & $80.90(6.72)$ & $0.33(0.11)$ & & $25.93(2.10)$ \\
\hline Paired Associates & $49.76(0.43)$ & $-0.39(0.08)$ & $-0.29(0.09)$ & $68.63(5.97)$ & $0.24(0.12)$ & & $33.49(2.60)$ \\
\hline Memory for Text & $49.97(0.39)$ & $-0.16(0.08)$ & $-0.36(0.10)$ & $49.39(5.20)$ & $0.27(0.13)$ & & $42.19(3.25)$ \\
\hline Category & $50.13(0.42)$ & $-0.62(0.07)$ & $-0.23(0.07)$ & $80.42(5.72)$ & $0.44(0.09)$ & & $23.95(0.98)$ \\
\hline Word Beginning & $49.91(0.42)$ & $-0.42(0.07)$ & $-0.28(0.09)$ & $65.69(5.91)$ & & & $37.75(2.47)$ \\
\hline Vocabulary & $50.06(0.42)$ & & $-0.33(0.07)$ & $75.68(5.86)$ & & & 23.49 (1.57) \\
\hline Spot a Word & $49.95(0.43)$ & $-0.22(0.07)$ & $-0.37(0.09)$ & $63.28(5.74)$ & & & $32.69(2.19)$ \\
\hline Close vision & $47.75(0.35)$ & $-1.10(0.09)$ & $-0.18(0.08)$ & $50.26(3.95)$ & $0.87(0.17)$ & & $25.32(1.38)$ \\
\hline Distant vision & $49.50(0.37)$ & $-0.48(0.11)$ & $-0.25(0.10)$ & $44.74(4.40)$ & $0.99(0.24)$ & & $48.93(2.64)$ \\
\hline Hearing & $50.50(0.41)$ & $-0.51(0.07)$ & $0.35(0.09)$ & $68.98(5.44)$ & & $0.59(0.18)$ & $30.34(1.62)$ \\
\hline
\end{tabular}

Note. Values in parentheses are standard errors.

This multivariate model was specified following the results of the 11 previous univariate RCMs. In particular, this model did not allow for the estimation of random effects in linear change for the Word Beginning, Vocabulary, and Spot-a-Word tasks or hearing and allowed for the estimation of random effects in quadratic change only for the Digit Letter task and hearing (both of which were not significant). For estimation purposes, three parameters had to be fixed in this model: the variance of linear change for Digit Letter and Identical Pictures and their covariance. The constraints, which were necessary to obtain estimation convergence, did not cause a loss in fit. All other parameters were freely estimated. As can be seen by comparing Tables 2 and 3, the analogous parameter estimates of the 11 univariate RCMs and of the multivariate RCM, respectively, were virtually equal in both sign and magnitude. However, the variances in quadratic change of Digit Letter and hearing were no longer reliably different from zero in the multivariate model. In addition to the parameters of the 11 univariate RCMs, the multivariate model also estimated all covariances defined among the levels and the linear changes of the different variables. The corresponding correlations are presented in the upper diagonal of Table 4 . This is an $18 \times 18$ matrix because of its 11 level and 7 change random effect components. All 55 level- level correlations were reliable, whereas 8 of the 20 estimated change-change correlations were not. Of the 77 level-change correlations, 36 were reliable. This matrix of covariances was then factor analyzed.

\section{Exploratory Factor Analysis Without Control for Age, Time to Death, and Risk of Dementia}

Given that decisions about the number of factors extracted in an EFA are somewhat arbitrary, we examined two possible solutions instead of one. First, we applied the common Kaiser-Guttman rule of one factor for each eigenvalue greater than 1 (see Appendix A for the corresponding scree plot). This led to our extracting four factors, whose standardized loadings are displayed in columns 2 through 5 of Table 5. Second, on the basis of our theoretical expectations, we specified two factors to be extracted, a Level factor presumably for all levels and a Change factor for all changes. These standardized loadings are presented in columns 6 and 7 of Table 5. In both EFAs, we specified a Promax rotation to allow for correlated factors.

In the four-factor solution, we obtained a Level factor for the cognitive variables (Level 1), a Change factor for the cognitive

Table 3

Multivariate Multilevel Modeling Results Without Control for Age, Time to Death, Risk of Dementia, and Their Interactions

\begin{tabular}{|c|c|c|c|c|c|c|}
\hline \multirow[b]{2}{*}{ Construct } & \multicolumn{3}{|c|}{ Mean } & \multicolumn{3}{|c|}{ Variance } \\
\hline & Level & Linear change & Quadratic change & Level & Linear change & Residual \\
\hline Digit Letter & $47.49(0.43)$ & $-0.91(0.07)$ & $-3.41(0.04)$ & $89.61(5.86)$ & 0.99 fixed & $8.81(0.33)$ \\
\hline Identical Pictures & $48.43(0.46)$ & $-0.61(0.07)$ & $-0.29(0.07)$ & $88.92(6.68)$ & 0.30 fixed & $24.10(1.60)$ \\
\hline Paired Associates & $49.37(0.43)$ & $-0.55(0.08)$ & $-0.24(0.08)$ & $72.49(5.98)$ & $0.42(0.19)$ & $31.40(2.37)$ \\
\hline Memory for Text & $49.44(0.38)$ & $-0.21(0.09)$ & $-0.24(0.09)$ & $49.76(4.90)$ & $0.31(0.14)$ & 41.14 (2.99) \\
\hline Category & $49.94(0.42)$ & $-0.64(0.07)$ & $-0.20(0.06)$ & $81.37(5.66)$ & $0.67(0.10)$ & $23.00(0.93)$ \\
\hline Word Beginning & $49.42(0.42)$ & $-0.44(0.07)$ & $-0.18(0.08)$ & $69.34(5.83)$ & & $35.80(2.26)$ \\
\hline Vocabulary & $49.81(0.43)$ & & $-0.26(0.07)$ & $78.16(5.86)$ & & $22.46(1.47)$ \\
\hline Spot a Word & $49.02(0.42)$ & $-0.25(0.07)$ & $-0.25(0.08)$ & $64.51(5.60)$ & & $32.56(2.12)$ \\
\hline Close vision & $47.34(0.34)$ & $-1.25(0.09)$ & & $48.46(3.77)$ & $0.92(0.16)$ & $25.72(1.36)$ \\
\hline Distant vision & $48.71(0.38)$ & $-0.67(0.10)$ & & $51.87(4.63)$ & $1.06(0.23)$ & $47.08(2.47)$ \\
\hline Hearing & $50.35(0.41)$ & $-0.49(0.06)$ & $0.35(0.07)$ & $70.17(5.38)$ & & $33.11(1.56)$ \\
\hline
\end{tabular}

Note. Values in parentheses are standard errors. 


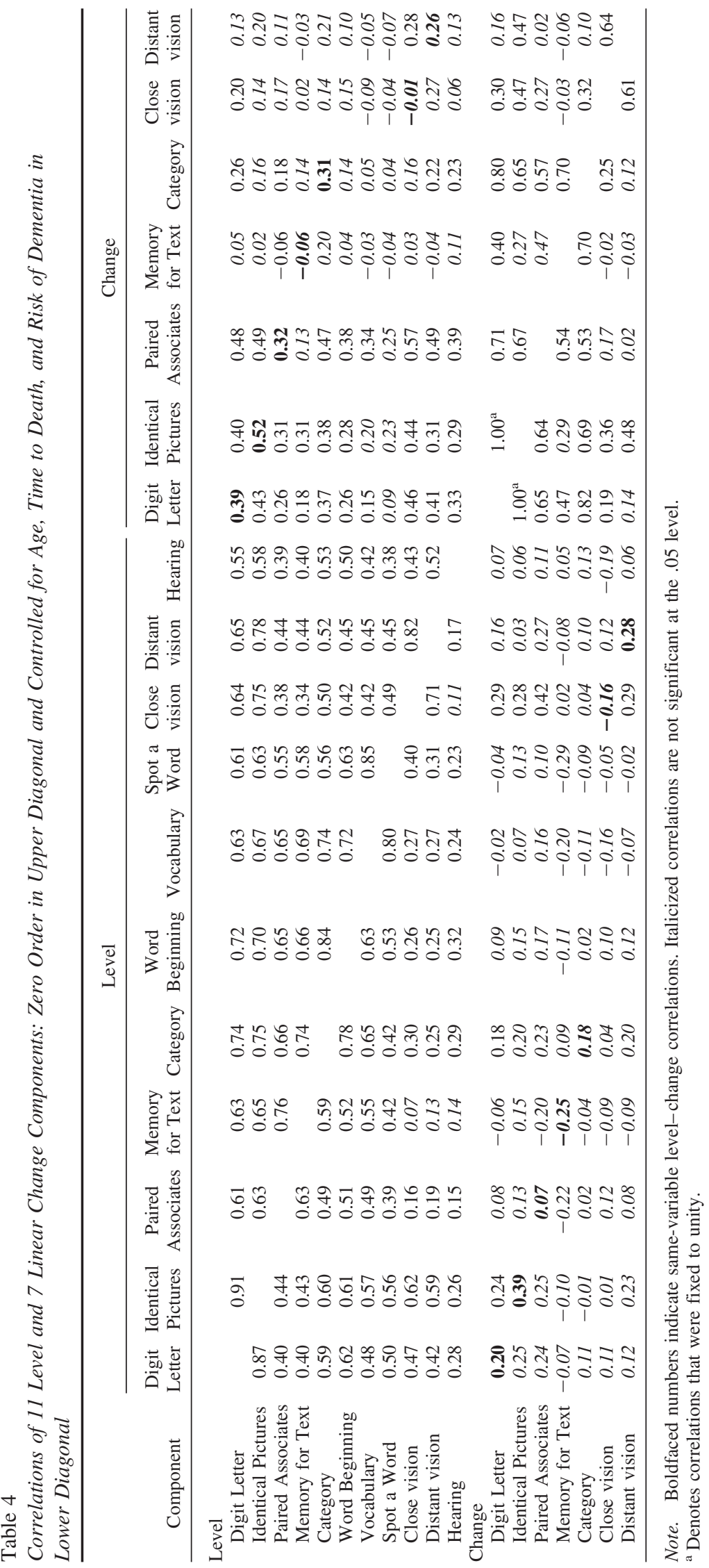


Table 5

Standardized Factor Loadings and Explained Variance From Exploratory Factor Analyses on the 11 Level and 7 Change Components Without Control for Age, Time to Death, Risk of Dementia, and Their Interactions

\begin{tabular}{|c|c|c|c|c|c|c|}
\hline \multirow[b]{2}{*}{ Component } & \multicolumn{4}{|c|}{ Four factors $\left(R^{2}=.72\right)$} & \multicolumn{2}{|c|}{ Two factors $\left(R^{2}=.58\right)$} \\
\hline & Level 1 & Change 1 & Level 2 & Change 2 & Level & Change \\
\hline \multicolumn{7}{|l|}{ Level } \\
\hline Digit Letter & 0.60 & 0.04 & 0.35 & 0.04 & 0.83 & 0.12 \\
\hline Identical Pictures & 0.53 & -0.02 & 0.54 & 0.04 & 0.88 & 0.13 \\
\hline Paired Associates & 0.81 & -0.01 & -0.07 & 0.12 & 0.76 & -0.02 \\
\hline Memory for Text & 0.92 & -0.04 & -0.13 & 0.01 & 0.82 & -0.15 \\
\hline Category & 0.83 & 0.16 & -0.01 & 0.04 & 0.82 & 0.10 \\
\hline Word Beginning & 0.86 & 0.01 & -0.02 & 0.05 & 0.84 & -0.04 \\
\hline Vocabulary & 0.89 & -0.05 & 0.04 & -0.19 & 0.91 & -0.22 \\
\hline Spot a Word & 0.71 & -0.11 & 0.17 & -0.13 & 0.82 & -0.20 \\
\hline Close vision & -0.04 & -0.01 & 1.02 & -0.09 & 0.58 & 0.24 \\
\hline Distant vision & 0.15 & -0.06 & 0.74 & 0.11 & 0.62 & 0.21 \\
\hline Hearing & 0.36 & 0.11 & 0.28 & -0.03 & 0.53 & 0.15 \\
\hline \multicolumn{7}{|l|}{ Change } \\
\hline Digit Letter & -0.07 & 0.82 & 0.23 & 0.10 & 0.02 & 0.96 \\
\hline Identical Pictures & 0.06 & 0.60 & 0.12 & 0.39 & 0.11 & 0.86 \\
\hline Paired Associates & 0.04 & 0.64 & 0.37 & -0.10 & 0.24 & 0.66 \\
\hline Memory for Text & -0.06 & 0.78 & -0.14 & -0.26 & -0.17 & 0.52 \\
\hline Category & -0.04 & 0.97 & -0.18 & 0.01 & -0.11 & 0.84 \\
\hline Close vision & 0.03 & 0.04 & -0.16 & 0.87 & -0.04 & 0.42 \\
\hline Distant vision & -0.09 & -0.18 & 0.13 & 0.80 & 0.03 & 0.29 \\
\hline \multicolumn{7}{|c|}{ Variance and interfactor $r$} \\
\hline & $61^{\mathrm{a}}$ & & & & $60^{\mathrm{a}}$ & \\
\hline & .25 & $60^{\mathrm{a}}$ & & & .36 & $48^{\mathrm{a}}$ \\
\hline & .56 & .36 & $56^{\mathrm{a}}$ & & $\mathrm{n} / \mathrm{a}$ & \\
\hline & .17 & .36 & .32 & $70^{\mathrm{a}}$ & $\mathrm{n} / \mathrm{a}$ & $\mathrm{n} / \mathrm{a}$ \\
\hline
\end{tabular}

${ }^{\text {a }}$ Percentage of variance explained by this factor in the variables loading on it.

variables (Change 1), a Level factor for the two vision variables (Level 2), and the associated Change factor in vision (Change 2). Level in hearing loaded weakly (0.36) on Factor 1 . The four factors accounted for $72 \%$ of the total variables' variance. The two Level factors correlated .56, whereas the two Change factors correlated .36 .

The two-factor solution, although more parsimonious, explained only $58 \%$ of the total variance, that is, $14 \%$ less than the fourfactor solution. It led to a clear overall Level factor (with loadings ranging from 0.53 to 0.91 , median $r=.82$ ) and a clear overall Change factor (with loadings ranging from 0.29 to 0.96 , median $r=.66$ ). The two factors correlated .36. In both EFAs, offloadings were very weak (generally close to $+/-0.10$ ).

\section{Univariate RCMs With Control for Age, Time to Death, and Risk of Dementia}

Table 6 displays the results of the 11 univariate RCMs carried out on the 8 cognitive and 3 sensory variables, controlling for the influences of age, time to death, risk of dementia diagnosis, their interactions, and their possible interactions with linear and quadratic change. As expected, the effect of age on level was highly significant for all variables (with effects ranging from a loss of 0.11 to $0.59 T$ points in cognition and a loss of 0.43 to $0.58 T$ points in sensory functioning for each additional year; see Table 6 , column 8 ). Time to death was a significant predictor of Identical Pictures, Category, Word Beginning, and distant vision, resulting in performance gains ranging from 0.24 to $0.59 T$ points for each additional year of life left (see Table 6, column 9; cf. Ghisletta et al., 2006). Dementia diagnosis affected all variables reliably, with effects ranging from -1.21 to $-7.40 T$ points (see Table 6, column 10). Because none of the possible interactions among the three covariates ended up being significant, they are not presented here. The three covariates reduced the variance in level of all variables, which now represents the variance residualized for age, time to death, and risk of dementia (see Table 6, column 5).

Age was a reliable predictor of linear change for Digit Letter, close vision, and hearing (see Table 6, column 11) and of quadratic change for Paired Associates (see Table 6, column 12). The mean linear change, after controlling for age, was not reliable for Memory for Text, Category, Vocabulary, and hearing (see Table 6, column 3), and the mean quadratic change was reliable for Digit Letter, Paired Associates, Category, Vocabulary, and Spot a Word (see Table 6, column 4).

\section{Multivariate RCM With Control for Age, Time to Death, and Risk of Dementia}

Table 7 displays the parameter estimates and standard errors of the multivariate RCM specified according to the preceding univariate RCMs with control for age, time to death, and risk of dementia. Age was again a significant predictor of all level components (with effects ranging from -0.68 to -0.31 ; see Table 7 , column 7) and of the linear change component of Digit Letter, Spot a Word, close vision, and hearing (with effects from -0.05 to 0.05; see Table 7, column 9). Time to death was no longer a 
significant predictor of either level or change. Risk of dementia predicted the levels of all cognitive variables (ranging in effects from -5.55 to -1.47 ; see Table 7 , column 8 ) but not the levels of sensory variables. This model obtained reliable mean linear change effects for all variables except for Memory for Text, Vocabulary, and hearing (see Table 7, column 3) and obtained reliable mean quadratic change effects for all variables except for close and distant vision (see Table 7, column 4). Again, all variances of levels were reliable (see Table 7, column 5), and the variances of linear change of Vocabulary, Spot a Word, and hearing were not reliable (see Table 7, column 6). Consequently, this multivariate RCM produced a variance-covariance matrix for 11 level and 7 linear change components. Again, the variances of linear change in Digit Letter and Identical Pictures, as well as their covariance, had to be fixed for empirical identification, with no loss in fit. By comparing Tables 6 and 7, it can be seen that the analogous parameter estimates of the 11 univariate RCMs and of the multivariate RCM with control for age, time to death, and risk of dementia, respectively, were almost identical, again lending further credibility to the parameter estimates of the multivariate model.

The lower diagonal of Table 4 portrays the $18 \times 18$ correlation matrix derived from this multivariate analysis. Of the 55 levellevel correlations, only 4 were not reliable. Of the 20 estimated change-change correlations, 13 were reliable, whereas of the 77 level-change correlations, 9 were still reliable. This covariance matrix was then factor analyzed.

\section{Factor Analysis With Control for Age, Time to Death, and Risk of Dementia}

Table 8 presents the standardized loadings of the EFA with control for the covariates. As before, the Kaiser-Guttman criterion suggested that four factors be extracted (see Appendix B for the corresponding scree plot). In the four-factor solution (see Table 8 , columns 2-5), we again obtained a Level factor for the cognitive variables (Level 1), a Change factor for the cognitive variables (Change 1), a Level factor for the two vision variables (Level 2), and the associated Change factor in vision (Change 2). Level in hearing loaded weakly $(0.28)$ on Level 1 . The four factors accounted for $64 \%$ of the total variables' variance, and the two Level factors still correlated .42 , whereas the two Change factors correlated 29 .

The two-factor solution (see Table 8, columns 6 and 7), although more parsimonious, explained $48 \%$ of the total variance (16\% less than the four-factor solution) and obtained a clear overall Level factor (with loadings ranging from 0.31 to 0.85 , median $=0.73$ ) and a clear overall Change factor (with loadings ranging from 0.27 to 0.96 , median $=0.70$ ). The two factors correlated .13. In both EFAs, the off-loadings were again very weak (generally close to $+/-0.10$ ).

\section{Discussion}

\section{Cognitive Changes Form a Strong Common Factor}

This article provides the first comprehensive report on the structure of cognitive and sensory changes in the BASE, including all longitudinally available cognitive and sensory variables and 
Table 7

Multivariate Multilevel Modeling Results With Control for Age, Time to Death, and Risk of Dementia

\begin{tabular}{|c|c|c|c|c|c|c|c|c|c|}
\hline \multirow[b]{2}{*}{ Construct } & \multicolumn{3}{|c|}{ Mean } & \multicolumn{2}{|c|}{ Variance } & \multirow[b]{2}{*}{ Age } & \multirow[b]{2}{*}{$\begin{array}{l}\text { Dementia } \\
\text { status }\end{array}$} & \multirow[b]{2}{*}{$\begin{array}{c}\text { Age } \times \text { Linear } \\
\text { Change }\end{array}$} & \multirow[b]{2}{*}{$\begin{array}{l}\text { Residual } \\
\text { variance }\end{array}$} \\
\hline & Level & $\begin{array}{l}\text { Linear } \\
\text { change }\end{array}$ & $\begin{array}{l}\text { Quadratic } \\
\text { change }\end{array}$ & Level & $\begin{array}{l}\text { Linear } \\
\text { change }\end{array}$ & & & & \\
\hline Digit Letter & $48.09(0.37)$ & $-0.81(0.09)$ & $-0.33(0.05)$ & $56.08(3.78)$ & 0.86 fixed & $-0.59(0.04)$ & $-1.80(0.42)$ & $-0.04(0.01)$ & $8.79(0.33)$ \\
\hline Identical Pictures & $48.88(0.40)$ & $-0.39(0.07)$ & $-0.31(0.07)$ & $46.67(4.08)$ & 0.25 fixed & $-0.68(0.04)$ & $-1.47(0.57)$ & & 24.99 (1.64) \\
\hline Paired Associates & $51.21(0.43)$ & $-0.21(0.08)$ & $-0.24(0.09)$ & $47.04(4.43)$ & $0.39(0.12)$ & $-0.32(0.04)$ & $-5.55(0.69)$ & & $31.34(2.37)$ \\
\hline Memory for Text & $50.65(0.40)$ & & $-0.22(0.09)$ & $31.53(3.80)$ & $0.37(0.14)$ & $-0.32(0.04)$ & $-3.92(0.66)$ & & $41.16(2.99)$ \\
\hline Category & $50.90(0.39)$ & $-0.41(0.07)$ & $-0.25(0.06)$ & $53.39(3.96)$ & $0.61(0.10)$ & $-0.47(0.04)$ & $-2.96(0.53)$ & & $23.07(0.96)$ \\
\hline Word Beginning & $50.21(0.44)$ & $-0.40(0.07)$ & $-0.17(0.08)$ & $53.59(4.87)$ & $0.88(0.22)$ & $-0.34(0.05)$ & $-2.33(0.67)$ & & $35.79(2.26)$ \\
\hline Vocabulary & $51.13(0.42)$ & & $-0.22(0.07)$ & $58.09(4.61)$ & & $-0.31(0.04)$ & $-4.13(0.61)$ & & $22.20(1.45)$ \\
\hline Spot a Word & $50.09(0.45)$ & $-0.20(0.07)$ & $-0.31(0.08)$ & $51.59(4.79)$ & & $-0.31(0.08)$ & $-3.24(0.69)$ & $-0.05(0.01)$ & $32.68(2.12)$ \\
\hline Close vision & $47.33(0.30)$ & $-1.37(0.11)$ & & $34.17(2.95)$ & $0.83(0.16)$ & $-0.44(0.04)$ & & $-0.03(0.01)$ & $25.87(1.42)$ \\
\hline Distant vision & $48.47(0.32)$ & $-0.56(0.11)$ & & $28.14(3.17)$ & $1.20(0.25)$ & $-0.59(0.04)$ & & & $44.79(2.45)$ \\
\hline Hearing & $50.07(0.34)$ & & $0.24(0.07)$ & $44.02(3.73)$ & & $-0.61(0.04)$ & & $0.05(0.01)$ & $30.60(1.50)$ \\
\hline
\end{tabular}

Note. Time to death was not significant. All possible interactions were not significant. Values in parentheses are standard errors.

covering six occasions of repeated measurements distributed over up to 13 years of longitudinal observation. The EFA of the variance-covariance matrix consisting of 11 level and 7 change variables led to a four-factor solution. In this solution, the 8 cognitive level variables and the 5 cognitive change variables each formed a factor on their own, revealing a remarkable similarity between the structure of change and the structure of level. The single factor of cognitive change accounted for $60 \%$ of the vari- ance in the 5 cognitive measures, showing reliable interindividual differences in change (Table 5). To illustrate the covariance in change, Figure 2 relates the longitudinal trajectories of Digit Letter to the longitudinal trajectories of Category. When controlling for age at first measurement, distance to death, and risk of dementia, the analogous factor accounted for $65 \%$ of the cognitive change variance (Table 8), indicating that the commonality in cognitive change was not a by-product of individual differences in any of the

Table 8

Standardized Factor Loadings and Explained Variance From Exploratory Factor Analyses on the 11 Level and 7 Change Components With Control for Age, Time to Death, and Risk of Dementia

\begin{tabular}{|c|c|c|c|c|c|c|}
\hline \multirow[b]{2}{*}{ Component } & \multicolumn{4}{|c|}{ Four factors $\left(R^{2}=.64\right)$} & \multicolumn{2}{|c|}{ Two factors $\left(R^{2}=.48\right)$} \\
\hline & Level 1 & Change 1 & Level 2 & Change 2 & Level & Change \\
\hline \multicolumn{7}{|l|}{ Level } \\
\hline Digit Letter & 0.55 & 0.05 & 0.34 & 0.05 & 0.76 & 0.12 \\
\hline Identical Pictures & 0.53 & 0.01 & 0.54 & 0.07 & 0.85 & 0.14 \\
\hline Paired Associates & 0.69 & -0.05 & -0.11 & 0.12 & 0.61 & -0.06 \\
\hline Memory for Text & 0.84 & -0.10 & -0.24 & -0.03 & 0.64 & -0.20 \\
\hline Category & 0.80 & 0.15 & -0.02 & 0.01 & 0.75 & -0.10 \\
\hline Word Beginning & 0.81 & 0.01 & 0.01 & 0.05 & 0.79 & -0.02 \\
\hline Vocabulary & 0.81 & -0.05 & 0.08 & -0.21 & 0.81 & -0.17 \\
\hline Spot a Word & 0.60 & -0.10 & 0.23 & -0.12 & 0.73 & -0.13 \\
\hline Close vision & -0.08 & 0.06 & 0.96 & -0.06 & 0.47 & 0.24 \\
\hline Distant vision & 0.01 & -0.07 & 0.72 & 0.11 & 0.45 & 0.14 \\
\hline Hearing & 0.28 & 0.11 & 0.08 & -0.14 & 0.31 & 0.05 \\
\hline \multicolumn{7}{|l|}{ Change } \\
\hline Digit Letter & 0.02 & 0.92 & 0.05 & 0.06 & 0.02 & 0.96 \\
\hline Identical Pictures & 0.14 & 0.74 & 0.01 & 0.34 & 0.15 & 0.87 \\
\hline Paired Associates & -0.02 & 0.70 & 0.28 & -0.11 & 0.12 & 0.70 \\
\hline Memory for Text & -0.17 & 0.73 & -0.06 & -0.24 & -0.24 & 0.59 \\
\hline Category & 0.03 & 0.91 & -0.17 & 0.01 & -0.10 & 0.84 \\
\hline Close vision & -0.03 & 0.01 & -0.13 & 0.80 & -0.02 & 0.29 \\
\hline Distant vision & -0.12 & -0.10 & 0.24 & 0.80 & 0.12 & 0.27 \\
\hline \multicolumn{7}{|c|}{ Variance and interfactor $r$} \\
\hline & $51^{\mathrm{a}}$ & & & & $45^{\mathrm{a}}$ & \\
\hline & .07 & $65^{\mathrm{a}}$ & & & 0.13 & $48^{\mathrm{a}}$ \\
\hline & .42 & .20 & $48^{\mathrm{a}}$ & & $\mathrm{n} / \mathrm{a}$ & \\
\hline & .13 & .29 & 0.15 & $64^{\mathrm{a}}$ & $\mathrm{n} / \mathrm{a}$ & $\mathrm{n} / \mathrm{a}$ \\
\hline
\end{tabular}

\footnotetext{
${ }^{\text {a }}$ Percentage of variance explained by this factor in the variables loading on it.
} 


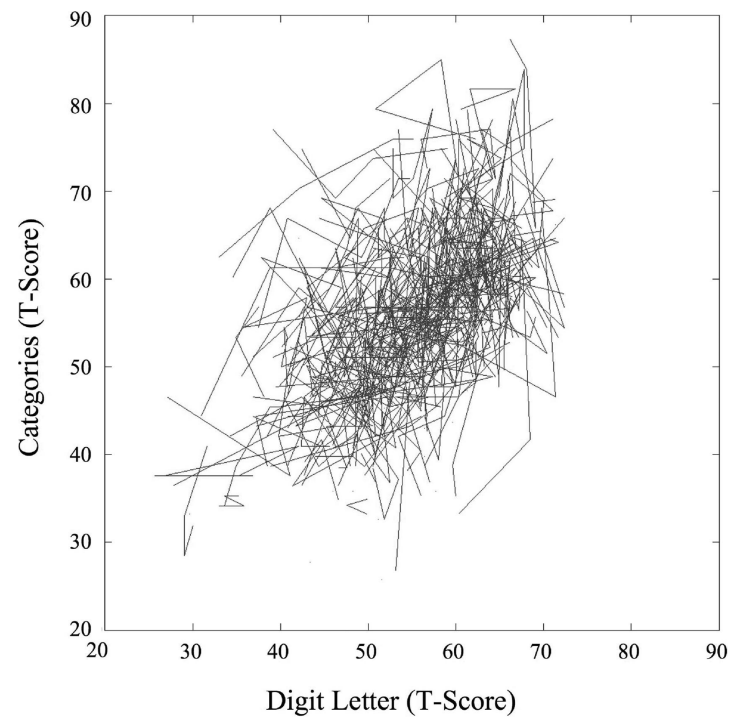

Figure 2. Longitudinal trajectories of Digit Letter and Categories performance. Only individuals assessed at more than one measurement occasion on both tests are represented in the figure. For each individual, lines connect measurement occasions adjacent in time. Individual differences in linear change between the two variables were correlated at $r=.80$.

normative or pathological alterations captured by age at first measurement, distance to death, or risk of dementia. Hence, the present findings provide remarkably clear support for theories of cognitive aging that posit domain-general mechanisms for senescent changes in cognition. The results also support the claim that measures of perceptual speed are particularly sensitive markers of cognitive aging (e.g., Salthouse, 1996) because changes in the two measures of perceptual speed-Digit Letter and Identical Pictures-were closely correlated and had very high loadings on the common change factors.

At the same time, the observed correlations in change among the cognitive variables also definitely allow room for domain-specific mechanisms of aging to operate. For instance, the loadings for the two tests of episodic memory-Paired Associates and Memory for Text-on the common cognitive change factor in the four-factor solution controlling for the three covariates were .70 and .73 , respectively (Table 8). Given that the EFA was based on latent factors, this result implies that a little less than half of the reliable variance in episodic memory change was not accounted for by the common cognitive change.

\section{Gauging the Cognitive-Sensory Link}

With respect to the link between cognitive and sensory declines, the results of this study are less clear. First, correlations to hearing loss could not be investigated because interindividual differences in hearing change were not statistically reliable. Second, of the remaining 10 correlations between cognitive and sensory changes (i.e., 5 cognitive changes $\times 2$ vision changes), 4 were statistically reliable, both without and with statistical control of covariates. In a four-factor solution of the overall correlation matrix, the two sensory measures with reliable variance in change-close and distant vision-formed a distinct factor of visual acuity change.
The correlation between the change factors for cognition and vision observed in the four-factor solution dropped from $r=.36$ to $r=.29$ when controlling for age, distance to death, and risk of dementia. When only two factors were extracted, close vision had a moderately high primary loading (0.42) and distant vision had a low primary loading (0.29) on a general, cognitively dominated change factor. When controlling for the three covariates, the loading of close vision on the general change factor of the two-factor solution dropped to $r=.29$, and the loading of distant vision dropped to $r=.27$.

To some extent, these results are consistent with the hypothesis that senescent changes in cognitive and sensory functioning are connected (e.g., Baltes \& Lindenberger, 1997; Ghisletta \& Lindenberger, 2005; Lindenberger \& Baltes, 1994; Nagel et al., 2007; Park et al., 2004). However, and in line with results reported by Anstey et al. (2003), the present results also suggest that these connections are weaker than originally suggested by crosssectional data (e.g., Baltes \& Lindenberger, 1997; Lindenberger \& Baltes, 1994). Previously observed cross-sectional correlations between sensory and cognitive domains of functioning were probably bolstered by the magnitude and similarity of negative age gradients in both domains, or by what Kalveram (1965) has termed the modification of factor structures through simultaneous superimposition (see also Hertzog, 1985; Hofer, Flaherty, \& Hoffman, 2006; Lindenberger \& Pötter, 1998; Lindenberger, von Oertzen, Ghisletta, \& Hertzog, 2008). Furthermore, given its reduction when controlling for the corresponding indicators, the link between cognitive and sensory decline is apparently augmented by age, distance to death, or risk of dementia (cf. Sliwinski et al., 1996; Sliwinski, Hofer, \& Hall, 2003).

When interpreting links between cognitive and sensory aging, functional and etiological classes of mechanisms need to be set apart (cf. K. Z. H. Li \& Lindenberger, 2002; Lindenberger, Marsiske, \& Baltes, 2000; McCoy et al., 2005; Rabbitt, 1993; Schäfer, Huxhold, \& Lindenberger, 2006). First, the functional link between sensory and cognitive domains is likely to increase with advancing adult age. As basic and coordinative sensory mechanisms become less efficient and more error prone with advancing age, sensory skills and sensory task demands may call for topdown mechanisms, such as sustained attention and executive control. This cognitive permeation of sensory and sensorimotor functioning (Lindenberger et al., 2000) results in increasing demands on decreasing cognitive resources because top-down mechanisms also deteriorate with advancing age (Craik, 1983). It is noteworthy that the developmental dynamics of this quandary would still lead to increasingly close connections between sensory and cognitive aspects of behavior even if the brain changes associated with functional losses in the two domains were fully separate.

Second, the etiological link between sensory and cognitive domains of functioning is also likely to increase with advancing adult age. The anatomical, chemical, and functional changes of the aging brain transcend the terminological and conceptual boundaries that separate sensory, motor, perceptual, and cognitive aspects of behavior (McIntosh, 2000). Aging brains undergo cerebral atrophy in the frontal cortex, gray matter loss, reductions in structural and functional connectivity, decreases in dopamine receptor density, and demyelination (for a summary, see Andrews-Hanna et al., 2007; Jagust \& D'Esposito, in press). If these changes are correlated and affect more than one domain of functioning, they 
limit performance across domains and qualify as a common cause (Lindenberger \& Baltes, 1994).

With this study, it is not possible to identify the relative size, interactions, and temporal sequence of functional and etiological contributions to the connection between cognitive and sensory declines. Earlier analyses of a subset of the present data, which examined the temporal dynamics of longitudinal change with multivariate dual-change score modeling, pointed to reciprocal rather than unidirectional dependencies between cognitive and visual decline, thereby providing evidence against the notion of a straightforward causal cascade from vision to cognition or from cognition to vision (Ghisletta \& Lindenberger, 2005). In light of the moderately high correlations between vision and cognitive declines observed in this study, we cannot exclude the possibility that the link between sensory and cognitive decline is primarily functional rather than etiological in nature. In keeping with this line of reasoning, the present results do not provide strong evidence for the operation of a common cause in visual and cognitive aging.

\section{Toward Unified Mechanistic Theories of Behavioral Decline in Old Age}

As noted in the introductory section, the data and analyses presented here provide correlational evidence on the relatively low dimensionality of behavioral decline without specifying the relevant underlying mechanisms. To conclude, we suggest desirable properties of such mechanisms and propose possible candidates. Comprehensive theories of behavioral senescence need to relate accuracy to latency, and variability to central tendency, at both behavioral and neuronal levels of analysis (e.g., Ratcliff, Schmiedek, \& McKoon, 2008; Ratcliff, Spieler, \& McKoon, 2000). In this vein, S.-C. Li and colleagues (e.g., S.-C. Li \& Lindenberger, 1999; S.-C. Li, Lindenberger, \& Sikström, 2001) proposed a neurocomputational theory of cognitive aging that integrates empirical evidence on senescent changes in behavior from psychometric, cognitive-experimental, and neuroscience research traditions (see also Braver et al., 2001; Nieuwenhuis et al., 2002). According to this theory, a large number of disparate manifestations of behavioral aging reflect senescent changes in dopaminergic neuromodulation, resulting in less distinct neuronal signaling, less separable processing pathways, and less differentiated cerebral representations. The neurocomputational theory proposed by S.-C. Li and colleagues also posits a direct link between variability and central tendency in cognitive performance, because the model parameter used to simulate age changes in dopaminergic neuromodulation affects both variability and central tendency (S.-C. Li \& Lindenberger, 1999; S.-C. Li et al., 2001). Similarly, applications of the diffusion model by Ratcliff and colleagues (e.g., Ratcliff \& Rouder, 1998; Smith \& Ratcliff, 2004) to behavioral aging highlight neural mechanisms that cause senescent changes in the variability of decision making and predict longitudinal decline in cognitive performance (e.g., Ratcliff, Thapar, Gomez, \& McKoon, 2004).

Evidence from several longitudinal studies supports the proposition that increasing processing fluctuations flag or predict mean level decline (Lindenberger \& von Oertzen, 2006; MacDonald, Nyberg, \& Bäckman, 2006). When examining age-related changes in processing fluctuations over 6 years in a group of individuals ages 75 to 89 years, MacDonald et al. (2003) reported sizeable correlations between changes in variability and changes in performance levels on tasks assessing working memory, perceptual speed, episodic memory, vocabulary, and reasoning. In a crosssectional correlational study with a life span sample of individuals ages 8 to 89 years, S.-C. Li et al. (2004) found that a similar measure of processing fluctuations uniquely predicted individual differences in fluid intelligence in old age, but not during earlier stages of the life span. Finally, in a recent analysis of data from the BASE, Lövdén et al. (2007) observed that higher trial-totrial variability in measures of perceptual speed preceded and predicted greater cognitive decline in levels of cognitive performance, whereas the reverse effect was not significant. In light of these findings, we suggest that the common factor of cognitive decline found in the present study supports the proposition that cognitive senescence can be characterized as a developmental cascade of less-distinct neuronal signaling, less separable processing pathways, and less differentiated cerebral representations (Andrews-Hanna et al., 2007; Park \& Reuter-Lorenz, 2009; cf. Kinsbourne \& Hicks, 1978).

\section{Limitations of This Study}

As with most psychometric work on developmental changes in behavior, the analyses reported in this study are based on the assumption of sample homogeneity (cf. Lindenberger \& von Oertzen, 2006; Molenaar \& Campbell, in press). RCM and latent growth curve modeling capture individual change in the context of population change. For instance, the random coefficient of linear change describes an individual's change trajectory as a deviation from the average linear change in the population. To the extent that individuals change in ways that are not captured by the normative trajectories prescribed by the statistical model, the corresponding variance and covariance terms may specify their true longitudinal changes incorrectly. In a related way, the present analyses are based on the assumption that a between-person phenomenon (i.e., the structure of interindividual differences in cognitive and sensory decline) can provide us with information about a within-person phenomenon (i.e., the causal dimensionality of senescent changes in brain and behavior). The tenability of this assumption is difficult to judge because sufficiently precise estimates of within-person factor structures are not yet available.

In the present analyses, correlations among levels and changes were nonnegative or positive, indicating that individuals with greater decline tended to show lower levels of functioning. This is consistent with the notion that levels of functioning in old and very old age reflect, to some extent, rates of earlier decline, which in turn predict rates of concurrent decline. Note that the present estimates of level-change covariances are unlikely to be biased in either a positive or a negative direction, given the centering procedure. However, the present analyses do not address the dynamics of behavioral aging, such as the issue of lead-lag relations within and across functional domains. The dual-change score model introduced by McArdle and Hamagami (2001) allows for the investigation of multivariate developmental dynamics in the context of longitudinal panel designs. This dynamic modeling technique has not, so far, been applied beyond the quadrivariate case (e.g., Ghisletta \& Lindenberger, 2005). With 11 variances of level and 7 
variances of change, the present variance-covariance matrix is too large to be tractable with this method.

Finally, in the present analyses, the length of time spent participating in the study, rather than chronological age, served as the basic time dimension used in RCM. This choice was made because of our interest in assessing individual differences in rates of change. One consequence of this data-analytic strategy is that retest effects cannot be estimated, given their perfect correlation with time in study in the research design of the BASE. The cognitive measures of the BASE have been scrutinized for retest effects in several earlier publications (e.g., Ghisletta et al., 2006; Lövdén et al., 2004). For instance, Lövdén et al. (2004) found that retest effects were absent for Digit Letter and Memory for Text and were present for Identical Pictures, Category, and Paired Associates, with significant variations in functional form from measure to measure. Given the individualized centering of the data in the present analyses, and the differences in the presence and shape of retest effects among the different measures, the correlations in change reported in this article cannot be due to correlated retest effects.

\section{Conclusion and Outlook}

In the present analysis of longitudinal changes in cognitive and sensory functioning in old and very old age, we found that $60 \%$ of the reliable variance in cognitive change was shared among five different cognitive tasks representing three different intellectual abilities-perceptual speed, episodic memory, and word fluency. When controlling for age at the first measurement, distance to death, and risk of dementia, $65 \%$ of the reliable variance in cognitive change was shared. We also found that visual acuity decline was moderately related to cognitive decline. At the same time, our findings indicate that the connection between sensory and cognitive aging may be weaker than suggested by crosssectional data. Nevertheless, the present findings support theories that conceive of behavioral senescence as a relatively lowdimensional process, in which a small number of causal pathways determine substantial portions of decline in a large number of different manifestations of behavior. Experimental investigations making use of animal models, genetic variation, pharmacological intervention, and behavioral training are needed to identify these major causes with greater precision and confidence. The present findings confirm that this search is well worth the effort.

\section{References}

Andrews-Hanna, J. R., Snyder, A. Z., Vincent, J. L., Lustig, C., Head, D., Raichle, M. E., et al. (2007). Disruption of large-scale brain systems in advanced aging. Neuron, 56, 924-935.

Anstey, K. J., Luszcz, M. A., \& Hofer, S. M. (2003). Cross-sectional and longitudinal patterns of dedifferentiation in late-life cognitive and sensory function: The effects of age, ability, attrition, and occasion of measurement. Journal of Experimental Psychology: General, 132, 470487.

Bäckman, L., Ginovart, N., Dixon, R. A., Wahlin, T. B. R., Wahlin, A., Halldin, C., \& Farde, L. (2000). Age-related cognitive deficits mediated by changes in the striatal dopamine system. American Journal of Psychiatry, 157, 635-637.

Bäckman, L., \& MacDonald, S. W. (2006). Death and cognition. European Psychologist, 11, 224-235.
Bäckman, L., Nyberg, L., Lindenberger, U., Li, S.-C., \& Farde, L. (2006). The correlative triad among aging, dopamine, and cognition: Current status and future projects. Neuroscience and Biobehavioral Reviews, 30, 791-807.

Bäckman, L., Small, B. J., Wahlin, A., \& Larsson, M. (2000). Cognitive functioning in very old age. In F. I. M. Craik \& T. A. Salthouse (Eds.), The handbook of aging and cognition (2nd ed., pp. 499-558). Mahwah, NJ: Erlbaum.

Baltes, P. B., \& Lindenberger, U. (1997). Emergence of a powerful connection between sensory and cognitive functions across the adult life span: A new window to the study of cognitive aging? Psychology and Aging, 12, 12-21.

Baltes, P. B., \& Mayer, K. U. (1999). The Berlin Aging Study: Aging from 70 to 100. New York: Cambridge University Press.

Braver, T. S., Barch, D. M., Keys, B. A., Carter, C. S., Cohen, J. D., Kaye, J. A., et al. (2001). Context processing in older adults: Evidence for a theory relating cognitive control to neurobiology in healthy aging. Journal of Experimental Psychology: General, 130, 746-763.

Brehmer, Y., Li, S.-C., Müller, V., von Oertzen, T., \& Lindenberger, U. (2007). Memory plasticity across the life span: Uncovering children's latent potential. Developmental Psychology, 43, 465-478.

Craik, F. I. M. (1983). On the transfer of information from temporary to permanent memory. Philosophical Transactions of the Royal Society of London, 302B, 341-359.

Craik, F. I. M., \& Bialystok, E. (Eds.). (2006). Lifespan cognition: Mechanisms of change. New York: Oxford University Press.

de Frias, C. M., Lövdén, M., Lindenberger, U., \& Nilsson, L.-G. (2007). Revisiting the dedifferentiation hypothesis with longitudinal multicohort data. Intelligence, 35, 381-392.

Erixon-Lindroth, N., Farde, L., Wahlin, T.-B. R., Sovago, J., Halldin, C., \& Bäckman, L. (2005). The role of the striatal dopamine transporter in cognitive aging. Psychiatry Research: Neuroimaging, 138, 1-12.

Gerstorf, D., Herlitz, A., \& Smith, J. (2006). Stability of cognitive sex differences in advanced old age: The role of education and attrition. Journal of Gerontology: Psychological Sciences, 61, 245-249.

Ghisletta, P., \& Lindenberger, U. (2003). Age-based structural dynamics between perceptual speed and knowledge in the Berlin Aging Study: Direct evidence for ability dedifferentiation in old age. Psychology and Aging, 18, 696-713.

Ghisletta, P., \& Lindenberger, U. (2004). Static and dynamic longitudinal structural analyses of cognitive changes in old age. Gerontology, 50, $12-16$.

Ghisletta, P., \& Lindenberger, U. (2005). Exploring structural dynamics within and between sensory and intellectual functioning in old and very old age: Longitudinal evidence from the Berlin Aging Study. Intelligence, 33, 555-597.

Ghisletta, P., McArdle, J. J., \& Lindenberger, U. (2006). Longitudinal cognition-survival relations in old and very old age. European Psychologist, 11, 204-223.

Helmchen, H., Baltes, M. M., Geiselmann, B., Kanowski, S., Linden, M., \& Reischies, F. M. (1999). Psychiatric illnesses in old age. In P. B. Baltes \& K. U. Mayer (Eds.), The Berlin Aging Study: Aging from 70 to 100 (pp. 167-196). New York: Cambridge University Press.

Hertzog, C. (1985). An individual differences perspective: Implications for cognitive research in gerontology. Research on Aging, 7, 7-45.

Hertzog, C., Lindenberger, U., Ghisletta, P., \& von Oertzen, T. (2006). On the power of multivariate latent growth curve models to detect individual differences in change. Psychological Methods, 11, 244-252.

Hertzog, C., von Oertzen, T., Ghisletta, P., \& Lindenberger, U. (2008). Evaluating the power of latent growth curve models to detect individual differences in change. Structural Equation Modeling, 15, 541-563.

Hofer, S. M., Flaherty, B. P., \& Hoffman, L. (2006). Cross-sectional analysis of time-dependent data: Mean-induced association in ageheterogeneous samples and an alternative method based on sequential 
narrow age-cohort samples. Multivariate Behavioral Research, 41, 165187.

Hultsch, D. F., Hertzog, C., Dixon, R. A., \& Small, B. J. (1998). Memory change in the aged. Cambridge, England: Cambridge University Press. Jagust, W., \& D'Esposito, M. (Eds.). (in press). Imaging the aging brain. Oxford, England: Oxford University Press.

Kalveram, K. T. (1965). Die Veränderung von Faktorenstrukturen durch "simultane Überlagerung" [The modification of factor structures through "simultaneous superimposition"]. Archiv für die gesamte Psychologie, 117, 296-305.

Kinsbourne, M., \& Hicks, R. E. (1978). Functional cerebral space: A model for overflow, transfer and interference effects in human performance: A tutorial review. In J. Requin (Ed.), Attention and performance VII (pp. 345-362). Hillsdale, NJ: Erlbaum.

Lövdén, M., Ghisletta, P., \& Lindenberger, U. (2004). Cognition in the Berlin Aging Study (BASE): The first 10 years. Aging, Neuropsychology, and Cognition, 11, 104-133.

Lövdén, M., Li, S.-C., Shing, Y. L., \& Lindenberger, U. (2007). Withinperson trial-to-trial variability precedes and predicts cognitive decline in old and very old age: Longitudinal data from the Berlin Aging Study. Neuropsychologia, 45, 2827-2838.

Li, K. Z. H., \& Lindenberger, U. (2002). Relations between aging sensory/ sensorimotor and cognitive functions. Neuroscience and Biobehavioral Reviews, 26, 777-783.

Li, S.-C., \& Lindenberger, U. (1999). Cross-level unification: A computational exploration of the link between deterioration of neurotransmitter systems and dedifferentiation of cognitive abilities in old age. In L.-G. Nilsson \& H. J. Markowitsch (Eds.), Cognitive neuroscience of memory (pp. 103-146). Kirkland, WA: Hogrefe \& Huber.

Li, S.-C., Lindenberger, U., Hommel, B., Aschersleben, G., Prinz, W., \& Baltes, P. B. (2004). Transformations in the couplings among intellectual abilities and constituent cognitive processes across the life span. Psychological Science, 15, 155-163.

Li, S.-C., Lindenberger, U., Nyberg, L., Heekeren, H. R., \& Bäckman, L. (in press). Dopaminergic modulation of cognition in human aging. In W. Jagust \& M. D'Esposito (Eds.), Imaging the aging brain. Oxford, England: Oxford University Press.

Li, S.-C., Lindenberger, U., \& Sikström, S. (2001). Aging cognition: From neuromodulation to representation. Trends in Cognitive Science, 5, 479486.

Lindenberger, U., \& Baltes, P. B. (1994). Sensory functioning and intelligence in old age: A strong connection. Psychology and Aging, 9, 339-355.

Lindenberger, U., \& Baltes, P. B. (1997). Intellectual functioning in old and very old age: Cross-sectional results from the Berlin Aging Study. Psychology and Aging, 12, 410-432.

Lindenberger, U., Marsiske, M., \& Baltes, P. B. (2000). Memorizing while walking: Increase in dual-task costs from young adulthood to old age. Psychology and Aging, 15, 417-436.

Lindenberger, U., Mayr, U., \& Kliegl, R. (1993). Speed and intelligence in old age. Psychology and Aging, 8, 207-220.

Lindenberger, U., \& Pötter, U. (1998). The complex nature of unique and shared effects in hierarchical linear regression: Implications for developmental psychology. Psychological Methods, 3, 218-230.

Lindenberger, U., Singer, T., \& Baltes, P. B. (2002). Longitudinal selectivity in aging populations: Separating mortality-associated versus experimental components in the Berlin Aging Study (BASE). Journal of Gerontology: Psychological Sciences, 57B, P474-P482.

Lindenberger, U., \& von Oertzen, T. (2006). Variability in cognitive aging: From taxonomy to theory. In F. I. M. Craik \& E. Bialystok (Eds.), Lifespan cognition: Mechanisms of change (pp. 297-314). New York: Oxford University Press.

Lindenberger, U., von Oertzen, T., Ghisletta, P., \& Hertzog, C. (2008).
Cross-sectional age variance extraction: What's change got to do with it? Manuscript submitted for publication.

MacDonald, S. W. S., Hultsch, D. F., \& Dixon, R. A. (2003). Performance variability is related to change in cognition: Evidence from the Victoria Longitudinal Study. Psychology and Aging, 18, 510-523.

MacDonald, S. W. S., Nyberg, L., \& Bäckman, L. (2006). Intra-individual variability in behavior: Links to brain structure, neurotransmission, and neuronal activity. Trends in Neurosciences, 29, 474-480.

Maier, H., \& Smith, J. (1999). Psychological predictors of mortality in old age. Journal of Gerontology: Psychological Sciences, 54, P44-P54.

Marsiske, M., Delius, J., Maas, I., Lindenberger, U., Scherer, H., \& Tesch-Römer, C. (1999). Sensory systems in old age. In P. B. Baltes \& K. U. Mayer (Eds.), The Berlin Aging Study: Aging from 70 to 100 (pp. 360-383). New York: Cambridge University Press.

McArdle, J. J., \& Hamagami, F. (1996). Multilevel models from a multiple group structural equation perspective. In G. A. Marcoulides \& R. E. Schumaker (Eds.), Advanced structural equation modeling. Issues and techniques. (pp. 89-124). Mahwah, NJ: Erlbaum.

McArdle, J. J., \& Hamagami, F. (2001). Latent difference score structural models for linear dynamic analyses with incomplete longitudinal data. In L. M. Collins \& A. G. Sayer (Eds.), New methods for the analysis of change (pp. 137-176). Washington, DC: American Psychological Association.

McCoy, S. L., Tun, P. A., Cox, L. C., Colangelo, M., Stewart, R. A., \& Wingfield, A. (2005). Hearing loss and perceptual effort: Downstream effects on older adults' memory for speech. Quarterly Journal of Experimental Psychology: Human Experimental Psychology, 58(A), 22 33.

McIntosh, A. R. (2000). Towards a network theory of cognition. Neural Networks, 13, 861-870.

Mehta, P. D., \& West, S. G. (2000). Putting the individual back into individual growth curves. Psychological Methods, 5, 23-43.

Molenaar, P. C. M., \& Campbell, C. G. (in press). The new person-specific paradigm in psychology. Current Directions in Psychological Science.

Nagel, I. E., Werkle-Bergner, M., Li, S.-C., \& Lindenberger, U. (2007). Perception. In J. E. Birren (Ed.), Encyclopedia of gerontology: Age, aging, and the aged (Vol. 2, 2nd ed., pp. 334-342). Amsterdam: Elsevier.

Nieuwenhuis, S., Ridderinkhof, K. R., Talsma, D., Coles, M. G. H., Holroyd, C. B., Kok, A., \& Molen, M. W. (2002). A computational account of altered error processing in older age: Dopamine and the error-related negativity. Cognitive, Affective, and Behavioral Neuroscience, 2, 19-36.

Park, D. C., \& Payer, D. (2006). Working memory across the adult lifespan. In F. I. M. Craik \& E. Bialystok (Eds.), Lifespan cognition: Mechanisms of change (pp. 128-142). New York: Oxford University Press.

Park, D. C., Polk, T. A., Park, R., Minear, M., Savage, A., \& Smith, M. R. (2004). Aging reduces neural specialization in ventral visual cortex. Proceedings of the National Academy of Sciences, 101, 13091-13095.

Park, D. C., \& Reuter-Lorenz, P. (2009). The adaptive brain: Aging and neurocognitive scaffolding. Annual Review of Psychology, 60, 173-196.

Rabbitt, P. (1993). Does it all go together when it goes? The nineteenth Bartlett Memorial Lecture. Quarterly Journal of Experimental Psychology, 46, 385-434.

Rabbitt, P., Lunn, M., Wong, D., \& Cobain, M. (2008). Age and ability affect practice gains in longitudinal studies of cognitive change. Journals of Gerontology: Psychological Sciences and Social Sciences, 63P, P235-P240.

Ratcliff, R., \& Rouder, J. N. (1998). Modeling response times for twochoice decisions. Psychological Science, 9, 347-356.

Ratcliff, R., Schmiedek, F., \& McKoon, G. (2008). A diffusion model explanation of the worst performance rule and IQ. Intelligence, 36, $10-17$. 
Ratcliff, R., Spieler, D., \& McKoon, G. (2000). Explicitly modeling the effects of aging on response time. Psychonomic Bulletin and Review, 7, $1-25$.

Ratcliff, R., Thapar, A., Gomez, P., \& McKoon, G. (2004). A diffusion model analysis of the effects of aging in the lexical-decision task. Psychology and Aging, 19, 278-289.

Raz, N., Lindenberger, U., Ghisletta, P., Rodrigue, K. M., Kennedy, K. M., \& Acker, J. D. (2008). Neuroanatomical correlates of fluid intelligence in healthy adults and persons with vascular risk factors. Cerebral Cortex, 18, 718-726.

Raz, N., Lindenberger, U., Rodrigue, K. M., Kennedy, K. M., Head, D., Williamson, A., et al. (2005). Regional brain changes in aging healthy adults: General trends, individual differences and modifiers. Cerebral Cortex, 15, 1676-1689.

Raz, N., Torres, I. J., \& Spencer, W. D. (1993). Pathoclysis in aging human cerebral cortex: Evidence from in vivo MRI morphometry. Psychobiology, 21, 151-160.

Rovine, M. J., \& Molenaar, P. C. M. (1998). The covariance between level and shape in the latent growth curve model with estimated basis vector coefficients. Methods of Psychological Research Online, 3, 95-107.

Salthouse, T. A. (1996). The processing-speed theory of adult age differences in cognition. Psychological Review, 103, 403-428.

Schäfer, S., Huxhold, O., \& Lindenberger, U. (2006). Healthy mind in healthy body? A review of sensorimotor-cognitive interdependencies in old age. EURAPA European Review of Aging and Physical Activity, 3, $45-54$.

Schaie, K. W., Maitland, S. B., Willis, S. L., \& Intrieri, R. C. (1998). Longitudinal invariance of adult psychometric ability factor structures across 7 years. Psychology and Aging, 13, 8-20.
Shing, Y. L., Werkle-Bergner, M., Li, S.-C., \& Lindenberger, U. (2008). Associative and strategic components of episodic memory: A life-span dissociation. Journal of Experimental Psychology: General, 137, 495513.

Singer, T., Verhaeghen, P., Ghisletta, P., Lindenberger, U., \& Baltes, P. B. (2003). The fate of cognition in very old age: Six-year longitudinal findings in the Berlin Aging Study (BASE). Psychology and Aging, 18, $318-331$.

Sliwinski, M. J., Hofer, S. M., \& Hall, C. (2003). Correlated and coupled cognitive change in older adults with and without preclinical dementia. Psychology and Aging, 18, 672-683.

Sliwinski, M. J., Lipton, R. B., Buschke, H., \& Stewart, W. (1996). The effects of preclinical dementia on estimates of normal cognitive functioning in aging. Journals of Gerontology: Psychological Sciences and Social Sciences, 50B, P162-P170.

Smith, P. L., \& Ratcliff, R. (2004). Psychology and neurobiology of simple decisions. Trends in Neurosciences, 27, 161-168.

Volkow, N. D., Gur, R. C., Wang, G.-J., Fowler, J. S., Moberg, P. J., Ding, Y.-S., et al. (1998). Association between decline in brain dopamine activity with age and cognitive and motor impairment in healthy individuals. American Journal of Psychiatry, 155, 344-349.

Wainer, H. (2000). The centercept: An estimable and meaningful regression parameter. Psychological Science, 11, 434-436.

West, R. L. (1996). An application of prefrontal cortex function theory to cognitive aging. Psychological Bulletin, 120, 272-292.

Wilson, R. S., Beckett, L. A., Barnes, L. L., Schneider, J. A., Bach, J., Evans, D. A., \& Bennett, D. A. (2002). Individual differences in rates of change in cognitive abilities in older persons. Psychology and Aging, 17 179-193. 
Appendix A

Scree Plot of Exploratory Factor Analysis Without Control for Age, Time to Death, and Risk of Dementia

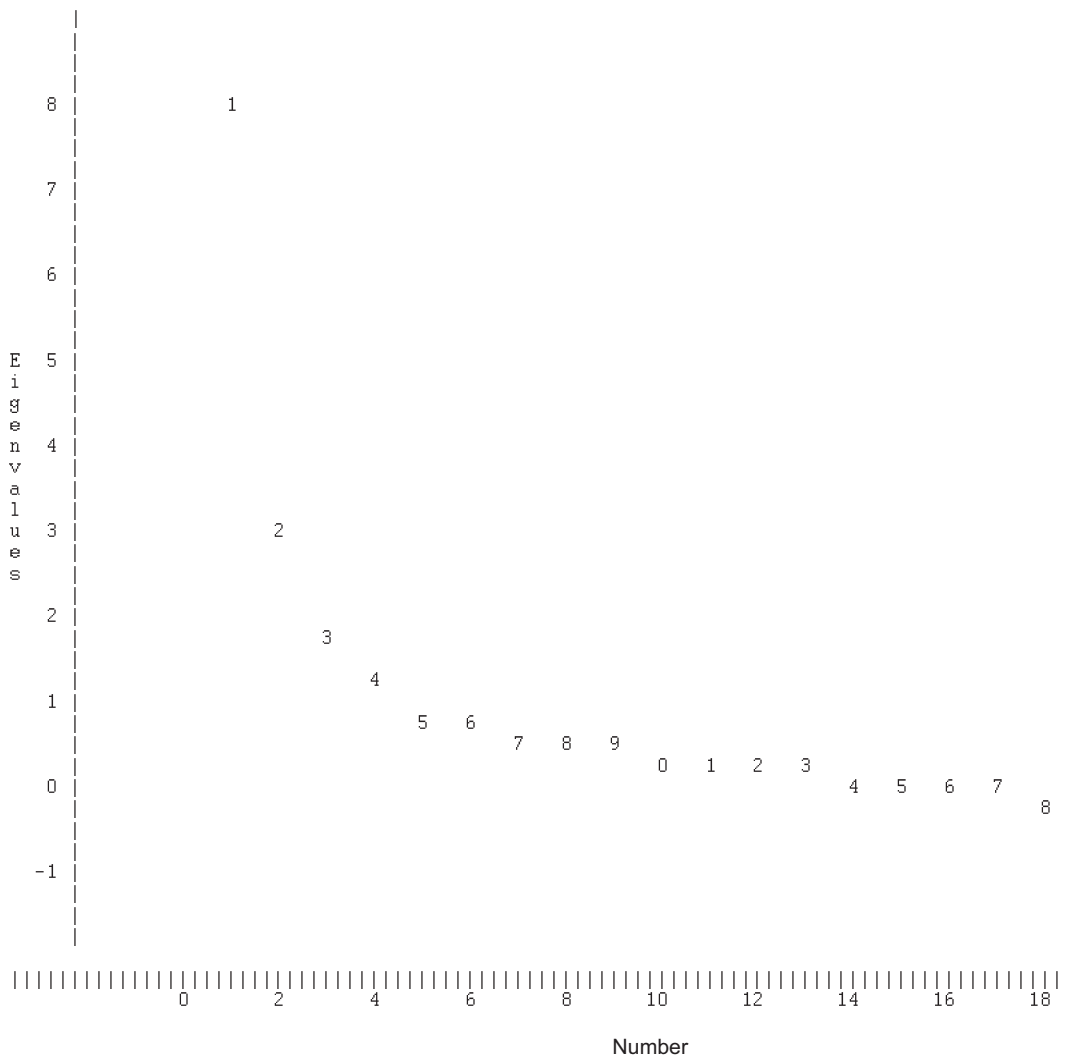

(Appendixes continue) 
Appendix B

Scree Plot of Exploratory Factor Analysis With Control for Age, Time to Death, and Risk of Dementia

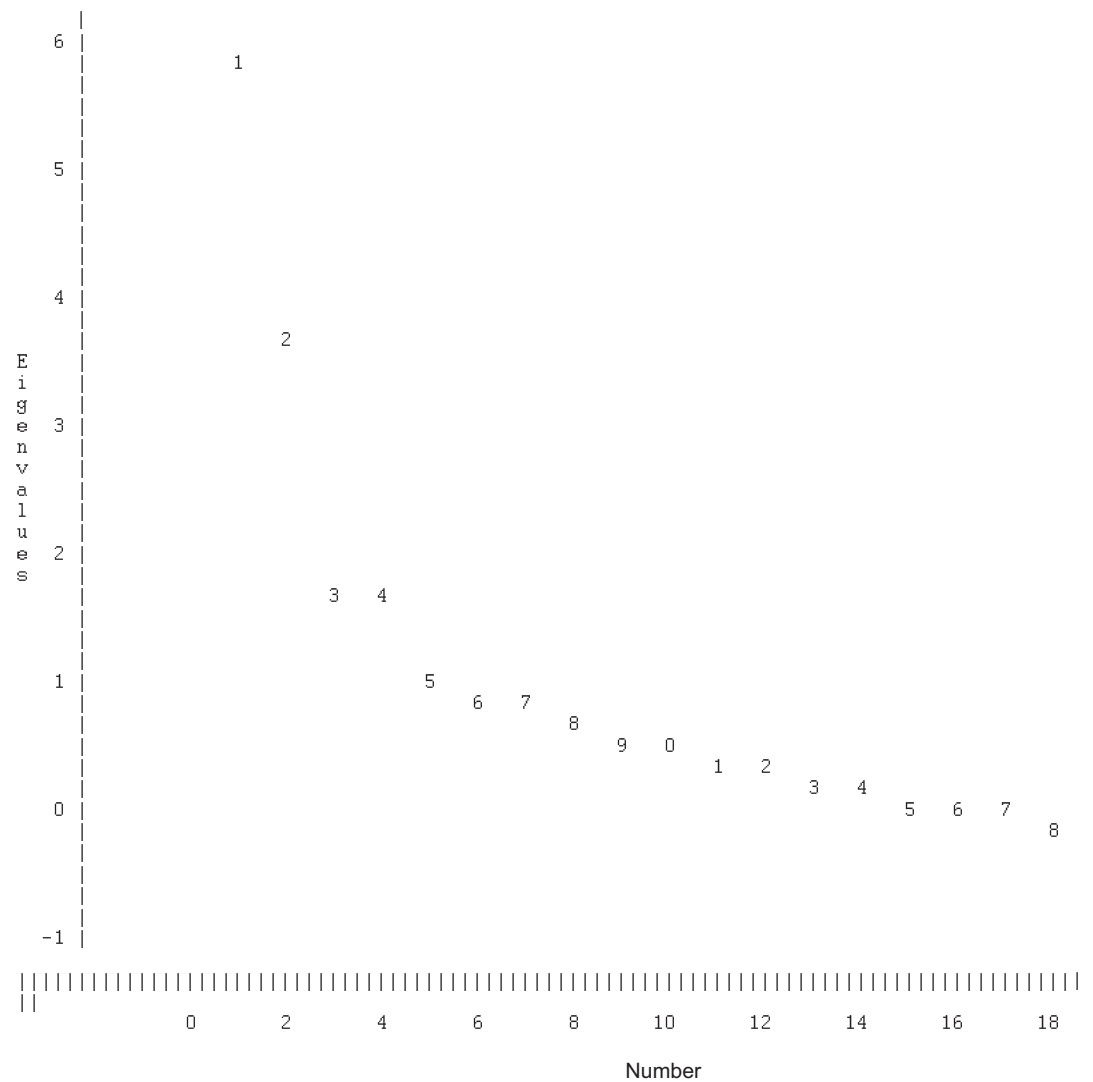

Received August 30, 2007

Revision received November 17, 2008

Accepted December 3, 2008 